\section{No correlation between the variants of exostosin 2 gene and type 2 diabetes in Burkina Faso population}

\author{
Serge Yannick Ouedraogo, ${ }^{1}$ \\ Daméhan Tchelougou, ${ }^{1}$ \\ Jonas Koudougou Kologo, ${ }^{2}$ \\ Herman Karim Sombie, ${ }^{1}$ \\ Moutanou Modeste Judes Zeye, \\ Rebeca Tégwindé Compaore, ${ }^{1,3}$ \\ Abdoul Karim Ouattara, ${ }^{1}$ \\ Abel Pegdwendé Sorgho, ${ }^{1}$ \\ Dorcas Obiri-Yeboah, \\ Serge Théophile Soubeiga, ${ }^{1}$ \\ Issoufou Nagabila, ${ }^{2}$ \\ Albert Théophane Yonli, 1,3 \\ Florencia Wendkuuni Djigma, 1,3 \\ Jacques Simpore ${ }^{1-3}$
}

${ }^{1}$ Laboratory of Molecular Biology and

Genetic (LABIOGENE), Ouagadougou,

Burkina Faso; ${ }^{2}$ Saint Camille Hospital

(HOSCO), Ouagadougou, Burkina-

Faso; ${ }^{3}$ Biomolecular Research Center

Pietro Annigoni (CERBA),

Ouagadougou; ${ }^{4}$ Department of

Microbiology and Immunology, School

of Medical Sciences, University of Cape

Coast, Ghana

\begin{abstract}
Recent genome-wide association studies and replication analyses have reported the association of variants of the exostosin2 gene (EXT2) and risk of type 2 diabetes (T2D) in some populations, but not in others. This study aimed to characterize the variants rs1113132, rs3740878 and rs11037909 of EXT2 and to determine the existence of a possible correlation with T2D in Burkina Faso. It is a case-control study undertaken in Burkina Faso in the city of Ouagadougou at the Hospital of Saint Camille of Ouagadougou from December 2014 to June 2015. It relates to 121 type 2 diabetes cases and 134 controls. The genotyping of these polymorphisms was done by real-time PCR using the allelic exclusion method with TaqMan probes. The minor allele frequencies (MAFs) was almost identical in diabetic and control subjects for the all three Single Nucleotide Polymorphisms (SNPs) with no statistical significance, $\mathrm{p}>0.05$ : $r$ s1113132 $(\mathrm{OR}=0.89 ; \mathrm{p}=0.82)$; rs11037909 $(\mathrm{OR}=0.89 ; \quad \mathrm{p}=0.74) \quad$ and $\mathrm{rs} 3740878(\mathrm{OR}=1.52 ; \mathrm{p}=0.42)$. None of the three polymorphisms studied was associated with the risk of DT2. However, an asso-
\end{abstract}

ciation between the BMI, age and type 2 diabetes was noted. The variants of EXT2 would not be associated to the risk of T2D in the African black population of Burkina Faso.

\section{Introduction}

Type 2 diabetes (T2D) is a public health issue on a worldwide scale characterized by chronic hyperglycemia. In 2017, the number of diabetics in Africa was estimated at approximately 15.9 million with a regional prevalence of $3.1 \%$; in Burkina Faso, this prevalence was estimated to be between $1.3-3.9 \% .^{1}$ In recent years, several genes have been identified as being risk factors for T2D. ${ }^{2,3}$ In 2007, a genome-wide association study identified multiples novel risk loci for T2D, among them were found Transcription Factor 7 Like 2 (TCF7L2), Solute Carrier Family 30 Member 8 (SLC30A8), Hematopoietically Expressed Homeobox (HHEX) and Exostosin 2 gene (EXT2). ${ }^{2}$ Hence, many studies have been conducted in various populations relating to some of these genes. ${ }^{4-6}$ The genome-wide association study conducted in the French population found a genetic association between EXT2 polymorphisms rs1113132, rs3740878, rs11037909, and T2D. ${ }^{2}$ Thereafter and in the context of different studies these associations were found in some populations such as the Caucasians but not in others such as the Asians, the African-Americans, the North Africans. ${ }^{4,7}$ 11 These contradictory results can be explained by ethnicity which is an important factor in genetic association studies. These results support the need for the replication of these association studies in various populations from different ethnic groups for a better understanding of these mechanisms. Some studies have been conducted on T2D and some candidate genes in Africa $^{12}$ but to our knowledge, none has focused on EXT2 and T2D in Burkina Faso population nor any other Sub-Saharan African countries. Therefore, the purposes of the present study is to determine the association between the three EXT2 genetics variants and the risk of the T2D within the Burkina Faso population.

\section{Materials and Methods}

\section{Study population}

It was a case-control study that was carried out from December 2014 to June 2015 in Burkina Faso in the city of Ouagadougou at the Hospital of Saint Camille of Ouagadougou (HOSCO). The study popula-
Correspondence: Dr. Florencia W. Djigma; Labiogene/Cerba, P. Box 7021 Ouagadougou 03, Burkina Faso.

E-mail: florencia.djigma@gmail.com;

Key words: Type 2 Diabetes; Exostosin-2; association; SNPs; Burkina Faso.

Contributions: Study Design: SYO; DT; JKK and JS. Sample collection: SYO; DT; HKS; IN and JKK. Treatment of samples: SYO; DT; HKS; MMJZ; RTC; AKO and APS. Analysis and interpretation of results: SYO; DT and STS. Writing and correction of the manuscript: SYO; DT; JKK; RTC; AKO; FWD; DOY; ATY and JS

Acknowledgments: We thank all the participants for their cooperation in this study. We also like to thank all staff of CERBA/LABIOGENE for their assistance.

Conflict of interest: The authors declare that they have no competing interests regarding the publication of this paper.

Funding: We would like to thank the West African Economic and Monetary Union (WAEMU) through PACER II program for their financial support.

Consent for publication: All the participant of this study gave their consent for a publication.

Ethics approval and consent to participate: This study was approved by the Institutional Ethical Committee of the Hospital of Saint Camille of Ouagadougou. Study approval number: 2014-7-012. Informed consent was obtained from all subjects before blood collection and all the data collected were processed confidentially.

Availability of data and materials: All data and materials are available within the text.

Received for publication: 28 August 2019.

Accepted for publication: 6 May 2020

This work is licensed under a Creative Commons Attribution NonCommercial 4.0 License (CC BY-NC 4.0).

(C) Copyright: the Author(s),2020

Licensee PAGEPress, Italy

Journal of Public Health in Africa 2020; 11:1233 doi:10.4081/jphia.2020.1233

tion consisted of 255 subject males and females whose ages ranged from 20 to 88 years old at a rate of 121 diabetic subjects (cases) and 134 non-diabetic subjects (controls). All the subjects were Burkinabe nationals from several cities of the country. The size and the weight were measured to determine each subject Body Mass Index (BMI). 


\section{Ethics approval}

This study was approved by the Institutional Ethical Committee of the Hospital of Saint Camille of Ouagadougou. Study approval number: 2014-7-012. Informed consent was obtained from all subjects before blood collection and all the data collected were processed confidentially.

\section{Blood collection, DNA extraction and genotyping of EXT2 variants}

Peripheral venous blood was sampled from each subject for various molecular and biochemical examinations. All DNA samples were extracted using standard salting out procedure. ${ }^{13}$ The quality and the concentration of the ADN obtained were measured by Biodrop $\mu$ LITE (Isogen Life Science, N.V/S.A, Temse, Belgium). The variants (rs3740878, rs11037909, and rs1113132) of EXT2 were genotyped using 20ng of DNA by the TaqMan assays (ABI, Applera International Inc, Foster City, CA, USA) in a reaction volume of $20 \mu \mathrm{L}$ (containing $0.5 \mu \mathrm{L}$ of $1 \mathrm{X}$ SNP Mix from Life Technologies), $10 \mu \mathrm{L}$ of TaqMan Universal Master Mix, $4.5 \mu \mathrm{L}$ of sterile Dnase free water and $5 \mu \mathrm{L}$ of DNA), on the ABI 7500 FAST real-time PCR systems (Applied Biosystems, California, USA).

\section{Statistical analysis}

Data were analyzed using SPSS 23.0 (IBM, USA) and Epi Info version 7 software (CDC, Atlanta, Georgia, USA). Software PLINK version 1.07 (Shawn Purcell,

URL: http://pngu.mgh.harvard.edu/purcell/plink) was used for the genetic tests of associations and to determine the equilibrium of Hardy-Weinberg for each studied polymorphism. Haploview version $4.1^{14}$ was used for the study of linkage disequilibrium on the level of various polymorphisms. The chi-square test was used for comparisons. The difference was considered significant for $\mathrm{P}<0.05$.

\section{Results}

\section{Study population characteristics}

Two hundred and fifty-five (255) subjects were included in this study and consisted of $42.7 \%(109 / 255)$ and $57.3 \%$ $(146 / 255)$ men and women, respectively. The subjects' ages ranged from 20 to 88 years old with more than $80.8 \%$ over 40 years (Table 1). The patients were on average older than the control subjects (54.72 \pm 11.35 against $50.90 \pm 13.97$ years old respectively).

\section{Association analysis}

Association case was not observed between studied SNPs (rs1113132, rs11037909, rs3740878) and the risk of developing T2D. Indeed, the minor allele frequencies (MAF) were statistically close between the cases and controls $(\mathrm{p}>0.05)$ (Table 2).

The haplotypic analysis of different studied SNPs revealed the existence of linkage disequilibrium between these three variants. The linkage appears stronger between SNPs rs11037909 and rs3740878 $($ from $=0.86)$ (Figure 1).

\section{Discussion}

In this study, there was no association between the EXT2 variants rs1113132, rs11037909 and rs3740878 and the risk of T2D in the Burkina population. Previous work carried out on the link between the EXT2 SNPs and the T2D reported diverging results according to the ethnicity of the studied populations. The average age of our study population was $54.72 \pm 11.35$ years for cases and $50.90 \pm 13.97$ years for controls which is similar to the study led by Yaméogo et al., in which the average age of diabetics was $53.50 \pm 3.50$ years. ${ }^{15}$ This average is similar to the UKPDS study ${ }^{16}$ where the average age was 54 years and to that of Nemr study in $2013^{9}$ (58 $\left.6 \pm 13.4\right)$. This supports the fact that T2D is related to age and usually occurs after 40 years. More than $31.30 \%$ of T2D subjects had a case of diabetes in their family, this is comparable to the $34.55 \%$ reported by Yanogo et al. ${ }^{17}$ and confirms the role of genetics in the occurrence of T2D. We did not find an association between EXT2 SNPs rs1113132, rs11037909 and rs3740878 and the risk of T2D development in our study population. Our results are inconsistent with those of the genome-wide association study led by Sladek et al. in 2007 on a French population ${ }^{2}$ and those of Liu et al.'s study. ${ }^{8}$ However, these results are consistent with other studies. . $^{7-11}$ This is the first study conducted on EXT2 variants related to T2D in Burkina Faso. Ethnicity is an important factor in genetic association studies and can

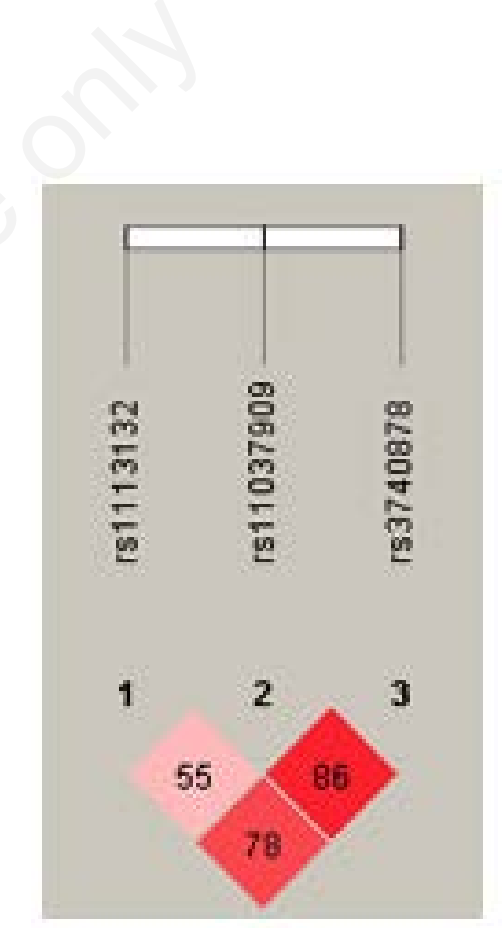

Figure 1. Linkage disequilibrium of EXT2 polymorphisms.

Table 1. General characteristics of the study subjects.

\begin{tabular}{|c|c|c|c|c|}
\hline & & Cases (diabetic) $n=121$ & Controls $\mathrm{n}=134$ & $P\left(\chi^{2}\right.$ test $)$ \\
\hline Sex & $\begin{array}{l}\text { Men } \\
\text { Women }\end{array}$ & $\begin{array}{l}36(29.8 \%) \\
85(70.2 \%)\end{array}$ & $\begin{array}{l}73(54.5 \%) \\
61(45.5 \%)\end{array}$ & $P<0.001$ \\
\hline Age & $\begin{array}{l}20-40 \text { years } \\
\geq 40 \text { years }\end{array}$ & $\begin{array}{c}14(11.6 \%) \\
107(88.4 \%)\end{array}$ & $\begin{array}{l}35(26.1 \%) \\
99(73.9 \%)\end{array}$ & $P=0.004$ \\
\hline $\mathrm{BMI}\left(\mathrm{kg} / \mathrm{m}^{2}\right)$ & $\begin{array}{l}\text { Underweight } \\
\text { Normal } \\
\text { Overweight } \\
\text { Obese }\end{array}$ & $\begin{array}{c}4(3.30 \%) \\
30(24.79 \%) \\
59(48.76 \%) \\
28(23.14 \%)\end{array}$ & $\begin{array}{l}24(17.90 \%) \\
73(54.48 \%) \\
31(15.67 \%) \\
16(13.22 \%)\end{array}$ & $\begin{array}{l}P<0.001 \\
P<0.001 \\
P<0.001 \\
P=0.02\end{array}$ \\
\hline HBP & $\begin{array}{l}\text { Presence } \\
\text { Absence }\end{array}$ & $\begin{array}{l}68(56.2 \%) \\
53(43.8 \%)\end{array}$ & - & \\
\hline Glucose (mn & & $7.86 \pm 3.474$ & $3.50 \pm 2.449$ & \\
\hline
\end{tabular}

BMI: Body Mass Index; underweight (under $18.5 \mathrm{~kg} / \mathrm{m} 2$ ), normal (18.5 to $25 \mathrm{~kg} / \mathrm{m}^{2}$ ), overweight (5 to $30 \mathrm{~kg} / \mathrm{m} 2$ ), obese (over $30 \mathrm{~kg} / \mathrm{m}^{2}$ ). HBP: High Blood Pressure / Hypertension. 
Table 2. Association between EXT2 and T2D in the study population.

\begin{tabular}{lccccccccc} 
CHR & SNP & Position $(\mathrm{pb})$ & Genotype & Normal allele & MAF* control & MAF case & OR \\
11 & rs1113132 & 44209979 & $\mathrm{C} / \mathrm{G}$ & $\mathrm{C}$ & 0.03358 & 0.03719 & 0.8996 & 0.82 \\
11 & $\mathrm{rs} 11037909$ & 44212190 & $\mathrm{~T} / \mathrm{C}$ & $\mathrm{T}$ & 0.0709 & 0.07851 & 0.8956 & 0.74 \\
\hline 11 & $\mathrm{rs} 3740878$ & 44214378 & $\mathrm{~A} / \mathrm{G}$ & $\mathrm{A}$ & 0.03731 & 0.02479 & 1.525 & 0.41 \\
\hline
\end{tabular}

CHR: Chromosome. *MAF: Minor Allele Frequencies; OR: Odds Ratio (with 95\% confidence intervals). SNP: Single Nucleotide Polymorphism

thus explain the divergent results in different studies. ${ }^{18,19}$ However, in our study, a correlation between T2D and BMI was observed. The BMI difference between cases and controls was statistically significant $(\mathrm{p}<0.05)$. Over $71.9 \%$ of the patients were overweight or obese with a mean $\mathrm{BMI} \geq 25 \mathrm{~kg} / \mathrm{m}^{2}$ or $26.9 \pm 8.4$. This result is similar to that of Nemr et al. study with $26.8 \pm 4.6$ and that of Diyane et al, with $28.1 \pm 4.6 .^{9,20}$ Finally, in our study we found that over $56.2 \%$ of T2D subjects had hypertension, this is comparable to the study conducted by Diyane et al. in 2013 where $60 \%$ of patients had grade I hypertension. ${ }^{20}$ The haplotype analysis of the three SNPs studied allowed us to demonstrate that in our study population the linkage appears stronger between SNPs rs 11037909 and rs3740878 with $86 \%$, for the others, we have $78 \%$ between rs1113132 and rs3740878; 55\% between rs1113132 and rs11037909.

\section{Conclusions}

This study suggests that polymorphisms of EXT2 does not play a very decisive role in the development of type 2 diabetes in a black population of Burkina Faso. It would be very important to carry out further studies in our population on a larger cohort while including other genes that are involved in the predisposition to T2D such as TCF7L2, SLC30A8, and HHEX. We believe that understanding the role played by these genes in the T2D pathogenesis will open multiple path for novel therapeutic strategies.

\section{Limitations}

One of the limitations of our study is the size of the study population. We believe that a larger number of cases and controls could have enabled to get a more specific and complete insight on the eventual correlation between T2D and EXT2 variants on our population.

\section{References}

1. International Diabetes Federation. IDF Diabetes Atlas, 8th edition. 2017.

2. Sladek R, Rocheleau G, Rung J, et al. A genome-wide association study identifies novel risk loci for type 2 diabetes. Nature 2007;445:881-5.

3. Zeng CP, Lin X, Peng $C$, et al. Identification of novel genetic variants for type 2 diabetes, childhood obesity, and their pleiotropic loci. J Hum Genet 2019;64:369-77.

4. Kifagi C, Makni K, Boudawara M, et al. Association of genetic variations in TCF7L2, SLC30A8, HHEX, LOC387761, and EXT2 with type 2 diabetes mellitus in Tunisia. Genet Test Mol Biomarkers 2011;15:399-405.

5. Park S, Liu M, Kang S. Alcohol Intake Interacts with CDKAL1, HHEX, and OAS3 Genetic Variants, Associated with the Risk of Type 2 Diabetes by Lowering Insulin Secretion in Korean Adults. Alcohol Clin Exp Res 2018;42:2326-36.

6. Kalantari S, Sharafshah A, Keshavarz P, et al. Single and multi-locus association study of TCF7L2 gene variants with susceptibility to type 2 diabetes mellitus in an Iranian population. Gene 2019;696:88-94.

7. Lewis JP, Palmer ND, Hicks PJ, et al. Association analysis in african americans of european-derived type 2 diabetes single nucleotide polymorphisms from whole-genome association studies. Diabetes 2008;57:2220-5.

8. Liu L, Yang X, Wang $\mathrm{H}$, et al. Association between variants of EXT2 and type 2 diabetes: A replication and meta-analysis. Hum Genet 2013;132: 139-45

9. Nemr R, Al-Busaidi AS, Sater MS, et al. Lack of replication of common EXT2 gene variants with susceptibility to type 2 diabetes in Lebanese Arabs. Diabetes Metab 2013;39:532-6.

10. Ren Q, Xiao J, Han X, et al. Impact of variants of the EXT2 gene on Type 2 diabetes and its related traits in the Chinese han population. Endocr Res 2015;40:79-82.
11. Takeuchi F, Serizawa M, Yamamoto K, et al. Confirmation of multiple risk loci and genetic impacts by a genome-wide association study of type 2 diabetes in the Japanese population. Diabetes 2009;58:1690-9.

12. Tekola-Ayele F, Adeyemo AA, Rotimi CN. Genetic epidemiology of type 2 diabetes and cardiovascular diseases in Africa. Prog Cardiovasc Dis 2013;56:251-60.

13. Miller SA, Dykes DD, Polesky HF. A simple salting out procedure for extracting DNA from human nucleated cells. Nucleic Acids Res 1988;16:1215.

14. Barrett JC, Fry B, Maller J, Daly MJ. Haploview: Analysis and visualization of LD and haplotype maps. Bioinformatics 2005;21:263-5.

15. Marceline YT, Issiaka S, Gilberte KC, et al. Diagnostic et prévalence du syndrome métabolique chez les diabétiques suivis dans un contexte de ressources limitées: Cas du Burkina-Faso. Pan Afr Med J 2014;19:364.

16. Turner R. Intensive blood-glucose control with sulphonylureas or insulin compared with conventional treatment and risk of complications in patients with type 2 diabetes (UKPDS 33). Lancet 1998;352:837-53.

17. Yanogo RDA, Sagna Y, Tieno H, et al. Prevalence of Diabetes and Cardiovascular Risk Factors in Ouagadougou (Burkina-Faso). OALib 2014;1:e595.

18. Ioannidis JPA, Patsopoulos NA, Evangelou E. Heterogeneity in metaanalyses of genome-wide association investigations. PLoS One 2007;2:e841.

19. Klimentidis YC, Abrams M, Wang J, et al. Natural selection at genomic regions associated with obesity and type-2 diabetes: East Asians and sub-Saharan Africans exhibit high levels of differentiation at type-2 diabetes regions. Hum Genet 2011;129:407-18.

20. Diyane K, El Ansari N, El Mghari G, Anzid K, Cherkaoui M. Caractéristiques de l'association diabète type 2 et hypertension artérielle chez le sujet âgé de 65 ans et plus. Pan Afr Med J 2013;14. 